\title{
Flèche d'Or de Django Reinhardt: porquê não foi ouvida?
}

\author{
Laurent Cugny (Université Paris-Sorbonne, França) \\ Laurent.Cugny@paris-sorbonne.fr \\ Tradução de Fabiano Araújo (UFES, Vitória, ES) \\ armoniah@gmail.com
}

Resumo: Este artigo apresenta uma revisão sobre aspectos históricos das circunstâncias em que foi gravada a música Flèche d'Or de Django Reinhardt, e como o músico francês era visto pelos críticos da época, nos Estados Unidos e na Europa. A partir da caracterização desta música como um claro exemplo anterior do que fora considerado como estopim do jazz modal em Miles Davis, levanta-se a questão: porquê ela não foi ouvida?

Palavras chave: violão de Django Reinhardt e Miles Davis; história do jazz modal e bebop; violão de Django Reinhardt; jazz modal e bebop na França.

\section{Flèche d'Or by Django Reinhardt: why was it not heard?}

Abstract: This article presents a criticism on historic aspects of the environment around the session of the tune Flèche d'Orby Django Reinhardt, and how critics considered the French musician at his time, both in America and Europe. After the demonstration that this piece is a true earlier example of what was considered the flame of the so called "modal jazz" with Miles Davis, the question takes place: Why was it not heard?

Keywords: Django Reinhardt and Miles Davis; history of bebop and modal jazz; guitar of Django Reinhardt, modal jazz and bebop in France.

\section{Para Frank Hagège}

\section{1 - Introdução}

30 de janeiro de 1952. Django Reinhardt está no estúdio da gravadora parisiense Decca, na companhia dos jovens franceses mais arrojados da era bebop: Roger Guérin (tp); Hubert Fol (alt sx); Raymond Fol (pn); Barney Spieler (bs); Pierre Lemarchand (bt). São gravadas quatro faixas: Keep Cool, Flèche d'Or, Troublant Boléro e Nuits de SaintGermain-des-Prés. A primeira, composição de Raymond Fol, as outras três, de sua autoria.

$\mathrm{Na}$ ocasião, Django encontrava-se em uma situação particularmente delicada. Sua turnê americana de 1946, embora tenha sido um ponto decisivo de sua carreira, não foi o sucesso esperado, e Django não se recuperaria tão cedo deste fracasso. Desde sua volta de Nova York, Django já não demonstrava mais o mesmo apetite pela música, e o público, os produtores e os programadores, também não Ihe manifestavam mais tanta atenção. Quando o selo Decca lhe propõe uma nova série de gravações, cuja primeira aconteceria em 11 de maio de 1951, Django não frequentava os estúdios desde a sessão Swing de 10 de março de 1948, ou seja, há três anos e dois meses. Esta sessão de 30 de janeiro de 1952 foi, portanto, a segunda pela Decca antes da terceira e última por este selo, que ocorreu exatamente uma ano mais tarde.

Django é cercado pela jovem guarda de músicos franceses, supostamente, os portadores da nova linguagem bebop. Com eles, Django fez a reabertura do clube SaintGermain em fins de fevereiro de 1951, mas, no caso, como convidado da orquestra de Hubert Fol. Quando entram em estúdio três anos mais tarde, pela Decca, o grupo é o mesmo (Bernard Hulin ao trompete, Hubert e Raymond Fol, Pierre Michelot e Pierre Lemarchand), mas desta vez sob o rótulo "Django Reinhardt e sua orquestra", o que comprova, se isto fosse necessário, que eles se escolheram mutuamente. A sessão de 1952 conta 
com a participação dos irmãos Fol e Lemarchand, mas, excepcionalmente, Roger Guérin substitui Bernard Hulin ao trompete e Barney Spieler substitui Michelot ao baixo.

Para muitos, Django é "coisa do passado", mesmo em termos de recursos musicais. Seu relativo afastamento, para não dizer desinteresse, no final dos anos 1940 the rendeu esta fama para com alguns. Implicitamente, suspeitava-se de sua capacidade de seguir o movimento do jazz encarnado pelo bebop. No entanto, a "velha raposa"1 não se deixou abater. Reinhardt teria confiado a seu amigo Pierre Fouad: "Um dia eu fiquei irritado, e comecei a tocar tão rápido que eles nem conseguiram me seguir! Mostrei a eles umas músicas novas, de harmonias difíceis, e eles também não conseguiram me acompanhar! Por isso, hoje, eles me respeitam!" (NEVERS, 2004).

Hoje em dia, é evidente que Django não era um "peixe fora d'água". Como será amplamente demonstrado na análise de seu solo em Flèche d'Or (CUGNY, 2014, veja artigo às p.12-20 neste volume de Per Musi), Django estava muito bem inteirado com a nova estética. Mas, o que queremos mostrar aqui é que, além disso, Django estava também um passo à frente deste trem (Ex.1), embora, talvez, não estivesse verdadeiramente ciente disto na época. 0 título de Flèche d'Or (Flecha de Ouro) deve-se provavelmente ao nome do trem que ligava Paris a Londres. É possivel que Django o tenha utilizado durante seu período de funcionamento: entre sua inauguração em 11 de setembro de 1926 e sua interrupção em 3 de setembro de 1939.

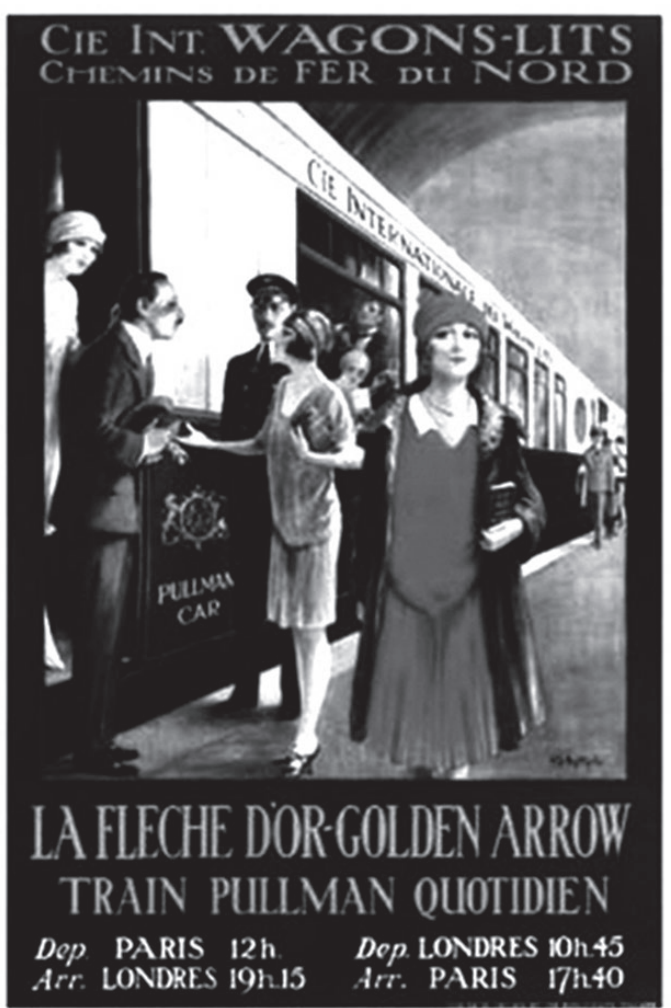

Ex.1 - Cartaz publicitário do trem Flèche d'Or-Golden Arrow, que ligava Paris a Londres e que, provavelmente, deu nome à música de Django Reinhardt.
A que nos referimos, exatamente? Neste caso, à sua composição Flèche d'Or. Com sua forma bastante incomum, Flèche d'Or talvez seja, inclusive, a primeira de seu gênero no jazz. Mais exatamente, não é a forma, mas a estrutura que é inédita. Trata-se, efetivamente, de uma forma AABBA que pode ser vista como uma variante estrutural da forma mais difundida nas composições de jazz, a AABA. Neste caso, seria um AABA com a ponte duplicada.

Mas isso não é tudo. Não há nesta música senão que um acorde na seção A (Si menor) e um na seção B (Mi com sétima). Ora, nesta época, não se fazia este tipo de coisa. Mesmo os "boppers", que transgrediam um pouco de tudo, não haviam pensado nisso. Ao contrário, em relação aos acordes, a tendência era de acrescentá-los às músicas. Se bem que Lennie Tristano já havia pensado, em 1949, em tocar sem nenhuma harmonia (TRISTANO, 1949). Havia também Jungle Blues de Jelly Roll Morton de 1927: esta ocorrera antes da invenção da forma tema - solos - tema. Porém, tocar (improvisar) sobre um acorde durante dezesseis ou vinte e quatro compassos fora um feito inédito. $E$ veremos que isso não aconteceu efetivamente, posto que a sessão rítmica acabara por se perder em seus caminhos harmônicos e a acrescentar dois tempos ao fim de uma das pontes ${ }^{2}$ de Flèche d'Or.

É exatamente com esse tipo de novidade que passouse a falar da introdução do "modal" no jazz. Que data é geralmente mencionada para se erguer este nascimento do "jazz modal"? 0 ano de 1958, com o lançamento de Milestones, de Miles Davis, o que precedeu em um ano a obra-prima de Miles em relação a este gênero: o álbum Kind of Blue. Tudo já expressado, aliás, pelas sessões do mesmo Davis para a trilha sonora do filme Ascenseur pour l'échafaud ${ }^{\beta}$ em 1957. Milestones, com justiça. Estrutura: AABBA. Harmonia: um acorde por seção. Impressiona, tamanha semelhança. Não tanto se estivesse em questão qualquer outra estrutura corrente, como o tipo AABA ou $A B A C$. Mas, AABBA, e ponte duplicada, não se encontra em nenhum exemplo anterior ${ }^{4}$.

Uma questão vem à tona, imediatamente: Miles Davis teria se inspirado em Flèche d'Orpara compor Milestones? Ou, ao menos, teria sido por ela cutucado? Não é o que pensa Lewis Porter, sob o argumento de que os discos de Django pelo selo Decca não eram disponíveis nos Estados Unidos até 1973, embora reconheça que Miles pudesse tê-la ouvido em sua temporada na França em 1957. No entanto, nosso objetivo aqui não é tanto de responder a esta pergunta, mas, antes, de tomar este caso como exemplo, investiga-lo, para levantar questão sobre a maneira como a história é escrita; como os eventos são percebidos; e como se elege os assim considerados: significativos. Em suma, refletir sobre este problema de recepção examinando, por exemplo, esta outra questão: que lugar as primeiras histórias do jazz reservaram a Django Reinhardt? 


\section{2 - 0 lugar de Django Reinhardt nas histórias do jazz}

Em um capitulo de seu livro Histoire du Jazz (de 1951) intitulado "figuras de transição" (entre o swing e o bop), eis o que Barry Ulanov escreve sobre...Charlie Christian:

\begin{abstract}
"Charlie [Christian] modificou a técnica da guitarra e garantiu a ela um papel de destaque no jazz, um papel jamais sonhado por Eddie Lang, Carl Kress e Dick McDonough, apesar de suas qualidades e imaginação. Ele deu a guitarristas como Barney Kessel, Wayne e Chuck Wayne e Billy Bauer, a possibilidade de pensar e expressarse, musicalmente, no mesmo nivel que os trombones, os trompetes e os saxofones. Ele transformou a guitarra de maneira tão eficaz, fazendo de um acompanhador rítmico um mestre eloquente, que até hoje poucas orquestras, pequenas ou grandes, conseguiram encontrar guitarristas tão capazes; depois de Christian, está fora de questão contentar-se com um guitarrista não competente." (ULANOV, 1951, p. 286).
\end{abstract}

Está bem claro, portanto, que, do ponto de vista da guitarra do jazz, Django Reinhardt...não existe, simplesmente. Contudo, um outro observador, mais advertido, Rudi Blesh, conhecia Django, e o cita em seu Shining Trumpets de 1946:

"Os puristas de jazz condenam sem duvidar a música do [Quinteto do] Hot Club [da França]. Porém, mesmo que não relacionada com os talentos naturais de músicos negros, essa música poderia bem ser um ponto de partida para um desenvolvimento branco menor exterior ao jazz. Extraordinário no Quinteto, é o cigano húngaro [sic] Django Reinhardt, que não é um guitarrista de jazz mas, por outro lado, é um bom artista improvisador." (BLESH, 1946, p. 270).

Portanto, desta vez Django existe. E até mesmo como um honorável improvisador, porém, enquanto "branco" e "húngaro", tudo o que ele pode aspirar é formar um secto distante das veredas reais do jazz. Felizmente, nem todos os julgamentos foram assim tão desdenhosos. $\mathrm{Na}$ coleção de artigos reagrupados no livro The Jazz Makers, publicado em 1958, Bill Simon consagra um artigo a Charlie Christian em que rende homenagem a Django:

\footnotetext{
"[...] quando o estilo de guitarra que consiste em tocar single notes, nota a nota [ e também em acordes] foi desenvolvido, tratavase de uma importação - diretamente da França. Seu advogado fora o cigano nascido na Bélgica, Django Reinhardt (1910-1953). Qual tenha sido sua influência, pouca ou muita, sobre [Charlie] Christian, ele faz jus, mais do que qualquer outro, ao fato de aceitar-se uma guitarra como solista, virtuose, e por quebrar a concepção desta como um instrumento puramente ritmico." (SIMON, 1958, p. 318).
}

Vê-se aqui nosso homem colocado em um papel mais eminente (e sua nacionalidade restaurada). No entanto...

\begin{abstract}
"Como guitarrista rítmico, de fato, Django era tristemente deficiente do ponto de vista dos cânones do jazz. Com apenas três dedos válidos na sua mão esquerda, ele era, por necessidade, mais um homem de single notes que de acordes. E ele era também o mais rápido." (Ibid., p. 318)
\end{abstract}

Certamente rápido, mas ainda assim um pouco limitado no acompanhamento ritmico. E, finalmente, eis a sentença:

\footnotetext{
"Mas as origens dos ancestrais de Django eram ciganas, e não escravos ou trabalhadores agrícolas. Ele aportou ao jazz novos elementos, exóticos e brilhantes. No entanto, nunca aproximou-se
}

do núcleo do jazz. Basta comparar as suas invenções esfumaçadas, embora férteis, com as improvisações potentes, terrestres do jovem [Charlie] Christian para compreender a diferença." (Ibid., p. 318).

Circulando! 0 animal é, de fato, surpreendente, mas não há nada de jazz para se ver! Quanto à guitarra elétrica, prefere-se não se demorar muito, em consideração para com nosso "velho de guerra"5:

"O papel de Django em uma pequena formação jazz era igualmente limitada pelo seu instrumento, que sempre fora a guitarra espanhola não amplificada. Alguns anos mais tarde, depois que [Charlie] Christian estabelecera a guitarra elétrica no jazz, Django converteu-se, mas nesta época ele perdeu muito de sua antiga autoridade ao tentar se adaptar aos novos sons do jazz da metade dos anos 1940." (/bid., p. 318)

Como justificativa, poder-se-á admitir que os autores americanos não estavam em contato direto de Europeus, e que os discos viajavam menos e com menos rapidez nesta época, sobretudo no sentido Europa - Estados Unidos. Mas, e quanto aos autores francofones?

Parece ter sido André Cœuroy o primeiro a citar Django, em sua Histoire générale du jazz - Strette - Hot - Swing, publicada em 1942. Mas o fez para apoiar sua tese absurda, segundo a qual o jazz é uma música inteiramente europeia, que não deve nada aos Afro-americanos: "Todos os brancos que tocam - Ekyan, Reinhardt - tocam swing, um swing próprio deles mesmo, um swing branco, um swing europeu, um swing "clássico", próximo em espírito da música de mesmo nome." (COEUROY, 1942, p.220). Aquilo que é geralmente censurável para os autores da época, é, para Couroy, digno de orgulho. Mas, vamos em frente. Segue-o de muito perto, em 1943, Huges Panassié, que, de sua parte, não tem muitas reservas:

\footnotetext{
"Em relação aos guitarristas, definitivamente, o melhor não é um negro, mas um francês, Django Reinhardt, cujo virtuosismo impressionante [...] alia-se um dom de invenção melódica, uma inspiração, um swing tal que pode-se sem hesitar, considerá-lo um dos maiores músicos de jazz." (PANASSIÉ, 1943, p.106).
}

Ainda mais espantoso, é o silencio de Robert Goffin sobre Django em sua Histoire du jazz, de 1945. Neste caso, o autor fala do jazz na Europa, mas unicamente para evocar os músicos americanos que lá firmaram residência. Nenhuma menção ao nosso cigano. Mesmo André Hodeir, de quem não se pode desconfiar de subestimar Django, não faz senão que uma rápida alusão ao guitarrista na sua Introduction à la musique de jazz, de 1947. Em um curtíssimo capítulo sobre o jazz na Europa, ele indica:

"Entre 1935 e 1939, a supremacia europeia pertence à França, onde se revelam duas personalidades cativantes: o guitarrista cigano Django Reinhardt e o violinista Stéphane Grappelli, solistas de uma pequena orquestra de cordas, o Quinteto do Hot Club da França. Numerosas gravações ocorreram em Paris, com o concurso Coleman Hawkins, Bennie Carter (Crazy Rhythm), de Bill Coleman, trompete de estilo deslumbrante, de invenção melódica inesgotável (Indiana), de Dickie Wells, trombone majestoso e comovente (Dicky Wells blues) e de outros músicos negros menos conhecidos, aos quais de juntaram os melhores franceses. Em seguida, a guerra, separando a França dos Estados Unidos, alimentara consideravelmente o desenvolvimento da escola francesa." (HODEIR, 1947, p.111). 
Django e Grappeli são, portanto, bem sinalizados, mas, entenda-se em sentido mais amplo, na medida em que estes tiveram a experiência de gravar com músicos americanos. Mais tarde, a escola francesa não teria outro destino senão que sofrer com a separação com a "navemãe", devido à guerra. Hodeir se redime mais tarde, publicando notadamente uma das primeiras (a primeira?) análises de um solo de Django, o de Solid Old Man, no número 88 de Jazz Hot (maio 1954)6.

\section{3 - Conclusão}

Para os musicólogos de jazz, coloca-se aqui a questão da "primeira vez". Qual é a primeira gravação de jazz "modal"? Seria preciso em primeiro lugar, um entendimento sobre o significado do termo, o que não se fará aqui. Nos contentaremos em evocar as músicas com ritmo harmônico bem lento, isto é, aquelas onde se permanece bastante tempo sobre um único acorde (o que não é evidentemente a mesma coisa que tocar "sobre os modos", mas infelizmente esta confusão se impõe fortemente). Poderíamos responder, Jungle Blues, de Jelly Rolll Morton de 1927. Ou talvez, Caravan (1937, nos primeiros compassos).

Flèche d'Or, certamente. Inclusive, se remontarmos a discografia anterior de Django (cujo virtuosismo à guitarra faz às vezes ofuscar que ele tenha sido um compositor impressionante), encontraremos outros sinais anunciadores. Começando em 1938, a música Appel indirect permanece oito compassos sobre uma harmonia de Dó com sétima (C7), e a ponte consiste na transposição tudo meio tom acima. Stéphane Grappelli toca seu solo claramente em modo mixolídio. Em 1943, como aponta Philippe Baudoin, a ponte de Douce ambiance faz entender quatro compassos de Lá menor com uma melodia francamente em modo dórico, seguidas dos mesmos dois primeiros compassos transpostos em um semi-tom, qual seja, um encadeamento idêntico àquele de So What. Outro caso é Diminushing, de 1947 (que deve-se encontrar sob os títulos Black Night em 1950 e Diminushing in Blackness em 1951) que não é, propriamente dizendo, modal, mas também não pode ser chamado de tonal. Assim como Impromptu (1951) ou Nuit de Saint-Germain-des-Prés (1952), estas peças exalam um forte perfume de algo que faz lembrar um outro "maldito" habituado aos caminhos de encruzilhada, Thelonious Monk.

A questão é, portanto, saber como devem ser considerados estes clarões isolados e anunciadores. Não é porque Lennie Tristano, a partir de 1949, gravou duas músicas com princípios análogos àqueles do free jazz que devemos marcar o início deste estilo à esta mesma data. É com a gravação do álbum epônimo, de Ornette Coleman, em 21 de setembro de 1960 que se inaugura, realmente, um estilo que irá se desenvolver e desabrochar a partir deste ponto. Deve-se dizer o mesmo de Flèche d'Or à respeito da nominação correta sobre o "jazz modal"? Não seria esta música, um traço (de gênio), eco no sentido inverso de uma aurora que não se perceberá senão que em Bill Evans, Miles Davis, Gil Evans, John Coltrane, seis, sete anos mais tarde? Talvez. Permanece entretanto, surdamente, a questão: porque não foi ouvida?

Agradecimento: Este artigo foi gentilmente cedido pela editoria de Les Cahiers du Jazz, onde foi publicado anteriormente com o título "Flèche d'Or": porquoi ne l'a ton pas entendu? na Nouvelle série, n.3, 2006, p.82-87.

\section{Referências}

BAUDOIN, Philippe. Chronologie du jazz. Paris: Outre Mesure, 2005.

CUGNY, Laurent, Analyser le jazz. Paris: Outre Mesure, 2009.

HODEIR, André. Introduction à la musique de jazz. Paris: Larousse, 1948.

NEVERS, Daniel. Django Reinhart:Troublant Boléro - 1950-1952. Integrale, v.19. Encarte de CD. Vincennes: Frémeaux \& Associés/Groupe Frémeaux Colombini SA, 2004 (CD FA319.).

PANASSIÉ, Hugues. La musique de jazz et le swing. Paris: Editora Corrêa, 1945.

SIMON, Bill. Charlie Christian. In: The Jazz Makers. Org. por Nat Hentoff e Nat Shapiro. Londres: Ed. Peter Davis, 1958.

ULANOV, Barry. A history of jazz. New York: Viking, 1951. Histoire du jazz. Trad. de Jean Sendy Paris: Corrëa/Buchet-Chastel, 1955.

\section{Referências de gravações}

COLEMAN, Ornette. Free Jazz. Atlantic: 1364, 1960. (LP)

DAVIS, Miles. Kind of blue. Columbia: CS 8163,1959. (LP)

Milestones. Columbia: CL 1193, 1958. (LP)

Ascenseur pour l'échafaud, Trilha Sonora do filme, Fontana, 1957 
ELLINGTON, Duke. Caravan. In: Ken Burns Jazz: Duke Ellington. Columbia/Legacy: CK 61444, 2000. (CD, faixa original de 1937)

MORTON,JellyRoll.JungleBlues.Victor:V21345A,1927.Disponívelem:<http://www.youtube.com/watch?v=t6u9NtauHAc>. Acesso em: 5 de abril de 2012.

REINHARDT, Django. Flèche d'Or. In: Intégrale Django Reinhart v. 12 Troublant Boléro - 1950-1952. Frémeaux \& Associés: FA 319 (CD2, faixa 12), 2004. (gravação original de 30 jan. 1952, Decca, Paris).

Appel indirect. In. Intégrale Django Reinhart v.8: Swing from Paris - 1938-1939. Frémeaux \& Associés: FA309, 2004. (CD1, faixa 14), 2004. (Gravação original de 14 jun. 1938)

Douce ambiance. In: Intégrale Django Reinhart v.12: Manoir de mes rêves 1943 - 1945, Frémeaux \& Associés: FA 312, (CD1, faixa 1), 2004. (Gravação original de 17 fev. 1943)

Diminushing. In: Intégrale Django Reinhart v.15: Gipsy with a song - 1947. Frémeaux \& Associés: FA 315. (CD2, faixa 11), 2004. (Gravação original de 14 nov.1947, Swing, Paris).__. Black Night. In: Intégrale Django Reinhart v.12 Troublant Boléro - 1950-1952. Frémeaux \& Associés: FA 319 (CD1, faixa 6), 2004. (Gravação original de abr./mai. de 1950 - RAI Studios, Rome

. Diminushing in Blackness. In: Intégrale Django Reinhart v.12 Troublant Boléro - 1950-1952. Frémeaux \& Associés:

FA 319 (CD2, faixa 1), 2004. (Gravação original de 20 fev. 1951, Club Saint-Germain, Paris).

. Impromptu, In: . In: Intégrale Django Reinhart v.12 Troublant Boléro - 1950-1952. Frémeaux \& Associés: FA 319

(CD2, faixa 7), 2004. (Gravação original de 11 mai. 1951, Decca, Paris).

Nuit de Saint Germain-des-Prés. In: Intégrale Django Reinhart v.12 Troublant Boléro - 1950-1952. Frémeaux \&

Associés: FA 319 (CD2, faixa 14), 2004. (gravação original de 30 jan. 1952, Decca, Paris).

TRISTANO, Lennie. Intuition e Digressions, Capitol,1949.

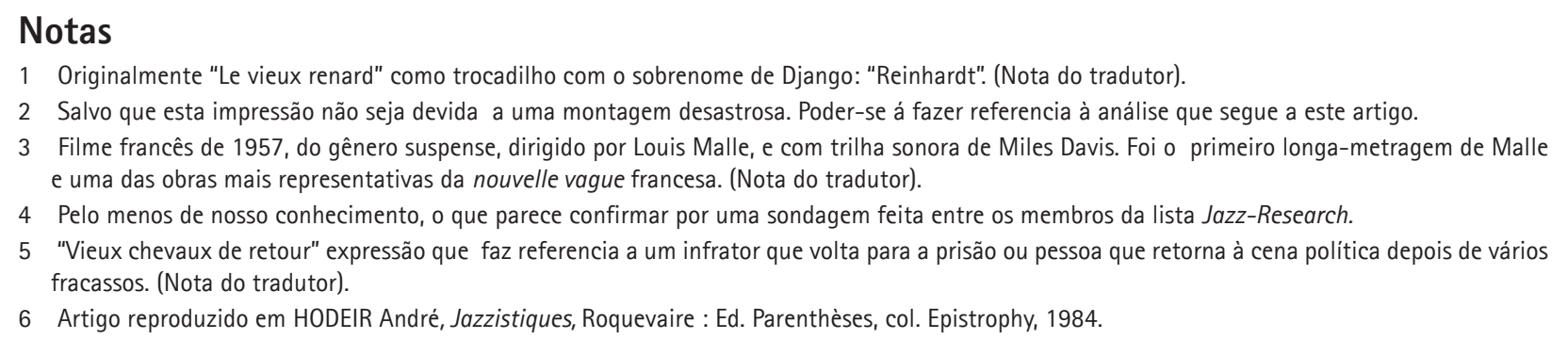

Laurent Cugny, pianista, arranjador e maestro, músico autodidata. Fundou a big band Lumière em 1979 e começou a gravar com esta orquestra a partir de 1981. Em 1987, toca e grava com Gil Evans, e de 1994 a 1997 dirige a Orquestra Nacional de Jazz. Trabalha também como arranjador, notadamente para Abbey Lincoln, Lucky Peterson, Juliette Gréco, David Linx, Ricardo Tepperman. Em 2006, criou no Festival Jazz à Vienne, a ópera-jazz La Tectonique des nuages que fora reapresentada no ano seguinte no Théatre de la Ville em Paris, e gravado em 2009 pelo selo Signature (Radio France). Neste mesmo ano, reformou a Enormous Band de vinte e três músicos que se apresentou nos Festivais de Vienne e de Marciac, e na Cité de la Musique. Em 2001, defendeu a tese de doutorado L'analyse de l'œuvre de jazz: spécificités théoriques et méthodologiques na Universidade Paris-Sorbonne (Paris IV), e em 2004, passou a coordenar pesquisas sobre História do jazz e Teoria do jazz. Professor Titular da Universidade Paris-Sorbonne desde 2006, Cugny é autor dos livros Las Vegas Tango: Une vie de Gil Evans (P.O.L., 1989, traduzido em japonês em 1996), Électrique: Miles davis 1968-1975 (André Dimanche, 1993, reedição Tractatus \& Co, 2009), Analyser le jazz (Outre Mesure, 2009). Coordena e é autor de uma coletânea sobre a história do jazz na França, patrocinada pela Agência Nacional da Pesquisa e pela Sacem.

Fabiano Araújo, pianista e compositor, desenvolve tese de doutorado sobre o jazz contemporâneo, desde 2012, na Universidade Paris-Sorbonne (Paris-IV), com bolsa CAPES, junto ao grupo JCMP-OMF (Jazz, chanson et musiques populaires - Observatoire Musical Français). É Mestre em Música pela Escola de Música da UFMG e Bacharel em Música Popular pelo Centro de Artes da UNICAMP. É Professor Assistente do Centro de Artes da Universidade Federal do Espírito Santo (UFES), onde contribuiu para a criação o curso de Bacharelado em Música, habilitação em Composição com ênfase em Trilha Musical. Lançou 4 CDs: $O$ Aleph (2007); Calendário do Som - 9 dias (2009) de Hermeto Pascoal, gravado e publicado em Portugal, com a participação do contrabaixista norueguês Arild Andersen do baterista Alexandre Frazão (Brasil/Portugal) e do saxofonista Guto Lucena (Brasil/Portugal); Rheomusi (2011) em trio com Arild Andersen e Naná Vasconcelos, e Baobab trio (2012), com peças de Radamés Gnattali, Baden Powell além de música improvisada em trio. 